\title{
Equations of Heat Generation during Friction Stir Welding for Tapered Polygonal Tools
}

Basim M. A. Al Bhadle ${ }^{1,2}$, Rafat A. A. Al Azzawi ${ }^{1,2}$, R. Thornton ${ }^{1}$, K. Beamish ${ }^{3}$, S. $\mathrm{Shi}^{3}$, H. B. Dong ${ }^{1 *}$

${ }^{1}$ Department of Engineering, University of Leicester, Leicester LE1 7RH, United Kingdom

${ }^{2}$ Technical Engineering College - Baghdad, Middle Technical University, Baghdad, Iraq

${ }^{3}$ TWI Ltd, Granta Park, Great Abington, Cambridge CB21 6AL, United Kingdom

*corresponding author: H.B. Dong

Professor H.B. Dong

Research Chair of Royal Academy of Engineering

Director of EPSRC CDT in Innovative Metal Processing

Science Director of TWI/UoL Materials Innovation Centre

Department of Engineering

University of Leicester

University Road, Leicester

LE1 7RH, UK

E-mail: h.dong@le.ac.uk

www.le.ac.uk/eg/hd38

www.impact.ac.uk 


\title{
Equations of Heat Generation during Friction Stir Welding for Tapered Polygonal Tools
}

\begin{abstract}
Due to the complex nature of heat generation in friction stir welding, equations are required to understand the effect of process parameters and tool geometry on heat generation. In this study, simplified equations for straight tool profiles have been extended to treat tapered tool profiles for triangular, square, pentagonal, and hexagonal geometries. New equations have been implemented to model heat generation in a finite element software package for welding aluminium alloy. The calculated thermal profiles agree better with experimental data than those calculated using the simplified equations. It was also demonstrated that the amount of heat generation increases with increasing number of flats on the tapered tool profile, with a hexagonal tapered tool profile generating the highest temperature.
\end{abstract}

Keywords: Friction stir welding (FSW), Heat generation, Taper tools, Taper tool factors.

\section{Introduction}

Friction stir welding (FSW) is classified as a solid state welding process and was invented by The Welding Institute (Cambridge, UK). The heat generation during FSW does not cause the base material to melt [1], but it is sufficient to soften the material so that a welding zone is formed due to the stirring force [2, 3]. Therefore the mechanisms by which heat is generated during FSW are significant factors in determining the quality of the final welded joints by predicting the effect of heat input on grain size of the nugget zone $[4,5]$.
Heat generation in FSW results from friction and deformation[6]. The heat generation depends on the contact condition. There are two main contact conditions. The sliding condition occurs when the contact shear stress at the toolworkpiece interface is less than the shear yield strength. The sticking condition occurs when the reverse is true. The combination of these contact conditions (partial sticking / partial sliding) is also possible [7].

Bastier et al. [8] reported that plastic deformation contributes $4.4 \%$ of the total 
heat generated. Therefore, several investigations [9-12] have assumed that heat is only generated as a result of frictional heat.

\section{The effect of tool geometry on heat generation during friction stir welding}

Tool geometry is a significant factor in controlling the heat generated during FSW $[1,13,14]$. The majority of pervious investigations have focused on the shoulder features (shoulder outer surface and shoulder end surface) because together they are responsible for more than $80 \%$ of the total heat generation $[1,7,15-17]$ during FSW processes.

Published studies have reported that changing FSW probe profiles increase the total heat generation. Schmidt, Hattel [7] reported that probe generated 14\% from total heat generation and $17 \%$ in a recent paper [17]. Zhang et al. [10] reported that the probe heat generation fraction differs by between 13 to $37 \%$ across a range of published FSW studies. As a result, many researchers have considered the impact of probe shape on the total heat generated. Ramanjaneyulu et al. [18] reported that the total heat generation and the peak temperature increases with increasing number of flats on the tool probe (i.e. triangular to hexagonal profile).
Recently, numerous FSW thermal models have been developed to determine the relationship between heat generation and tool profile $[11,12,19,20]$. However, tapered polygonal profiles have not yet been considered. To address this gap, in the present work analytical models are developed, which give a complete description of the influence of the polygonal tapered probe profiles on the total heat generated. These models are implemented using COMSOL (a commercial finite element package) and compared with published results from experimentation and modelling.

\section{Equations for heat generation}

Friction stir welding can be considered as the combination extrusion, forging, and stirring processes, occurring simultaneously, which results in the generation of high temperatures and strain rates [21]. Generally, the heat generated during the FSW process was considered to be a result of the friction process between the welding tool and base metal [8], but practically it is due to friction as well as deformation. In the present work, equations are derived to calculate the heat input and contribution at surfaces (shoulder, probe side and probe tip) for different tapered tool profiles, (triangular (TR), square (SQ), pentagonal (PEN) and hexagonal (HEX) which are shown in Figure 1. The tool 
dimensions (shoulder radius $\left(\mathrm{R}_{\mathrm{s}}\right) 6 \mathrm{~mm}$, probe radius $\left(R_{p}\right) 3 \mathrm{~mm}$, probe hight $\left(H_{p}\right)$ $4.7 \mathrm{~mm}$ and taper angle $14^{\circ}$ ) were selected to allow validation against the practical study by Ramanjaneyulu et al. [18]. The derived equations were applied in COMSOL 5.1 to calculate the temperature evolution in FSW for the selected taper probe profiles.

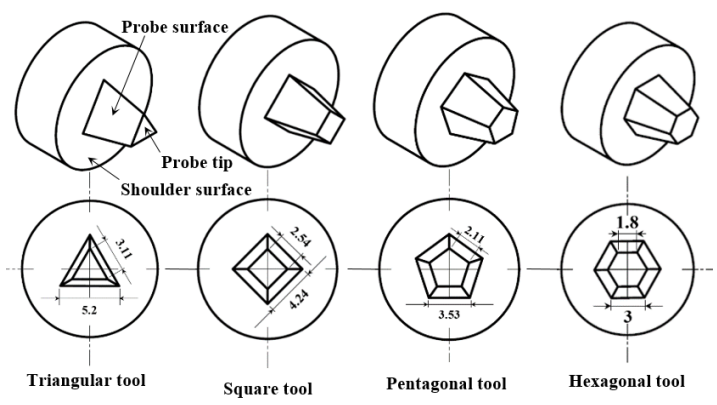

Figure 1. Geometry of various taper tool profiles.

\section{Heat Generation Equation for}

\section{Taper Tools}

In the analytical estimation for all taper tools, a circular flat cross-section shoulder surface, a sloping trapezoidal prism probe side surface, and a flat probe tip crosssection surface are assumed. The simplified tool design for the taper tools is presented in Figure 1, where $Q_{1}$ is the heat generated under the tool shoulder, $Q_{2}$ is the heat generated at the tool trapezoidal probe side, and $Q_{3}$ is the heat generated at the tool probe tip. Hence the total heat generated can be expressed, $Q_{\text {total }}=Q_{1}+Q_{2}+Q_{3}$.
The heat generation expression for each surface is different but based on same heat generation equation (Equation 1) [16]:

$$
\partial Q=\omega \cdot \partial M=\omega \cdot x \cdot \partial F=\omega \cdot x \cdot \tau_{c o n} . \partial A
$$

Where $M$ is a moment, $F$ is a force, $\omega$ is angular velocity, $A$ is contact area, $x$ is shear force arm and $\tau_{c o n}$ is the contact shear stress.

The value of contact shear stress is assumed according to the contact condition. In this work, it is assumed to be due to the friction at the shoulder surface as it slides along the weld material. Coulomb's friction law is therefore used to estimate friction shear stress for a sliding condition $\tau_{\text {con }}=\tau_{\mathrm{sl}}=$ $\mu$. P. The sticking condition is assumed at the probe and probe tip surfaces because they contact with softening layers. Therefore, in these cases, the contact shear stress is given by the von Mises yield criterion $\tau_{\mathrm{con}}=\tau_{\mathrm{st}}=\frac{\sigma_{\mathrm{y}}}{\sqrt{3}}$.

$\mathrm{dA}$ is the element of the cross section area between matrix and tool surface. This element is expressed by its location and direction relative to tool rotation axis as shown in Figure 2. Circular and rectangular elements are used to calculate areas of the shoulder, probe base and probe tip (Figure 2 (a) and (c)). 


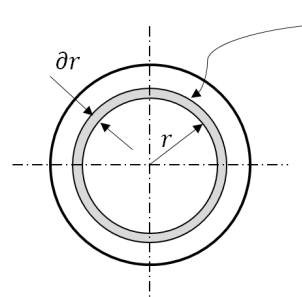

(a)

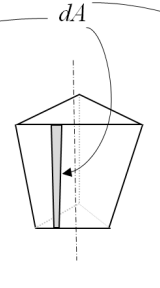

(b)

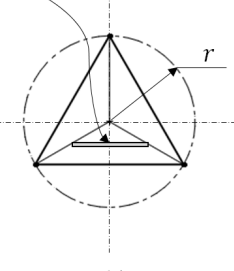

(c)
Figure 2. Schematic drawing of surface orientations and infinitesimal segment. (a) Shoulder surface area, (b) Probe surface area and (c) Probe base and tip crosssection area.

Probe base and tip cross section element area $\mathrm{dA}$ are calculated by dividing this area to many triangles depending on number of flats $(\mathrm{N})$ as shown in Figure 3. dA can be calculated by:

$$
\partial A=N . d A_{\text {one }}=N \cdot w_{i} \cdot \partial R_{\text {in }}
$$

Where $\mathrm{w}_{\mathrm{i}}$ is the width of element, $\partial R_{\text {in }}$ is a height of element, it is equalled the change in radius of inscribed circle.

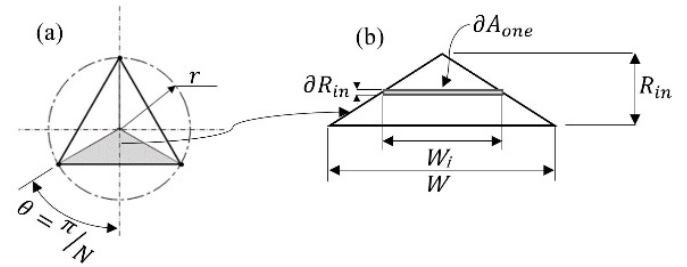

Figure 3. Schematic drawing for probe base. (a) The triangular probe base cross section. (b) Schematic drawing for Position and dimensions of segment.

From Figure 3, $\mathrm{w}_{\mathrm{i}}$ is:

$$
w_{i}=2 \cdot r \cdot \sin \theta
$$

While $\partial R_{\text {in }}$ is calculated by:

$$
\partial R_{\text {in }}=\partial r \cdot \cos \theta
$$

dA can be simplified by substitution equation (3) and equation (4) at equation (2):

$$
\partial A=2 \cdot N \cdot \sin \theta \cdot \cos \theta \cdot r . \partial r
$$

From equation (5) the area factor $\mathrm{F}_{\mathrm{A}}$ is:

$$
F_{A}=2 \cdot N \cdot \sin \theta \cdot \cos \theta
$$

Finally, the equation (5) can be rewritten as:

$$
\partial A=F_{A} \cdot r \cdot \partial r(7)
$$

The $\mathrm{F}_{\mathrm{A}}$ value is listed in Table 1.

While the lateral probe surface area can be estimated by using isosceles trapezoidal elements (Figure 2 (b)). Polygonal probe surface area relies on a probe flats number, so probe surface area element (dA) calculates by:

$$
\partial A=N \cdot d A_{F}(8)
$$

Where $d A_{F}$ is the area for one flat and $\mathrm{N}$ is number of flats on probe surface. 


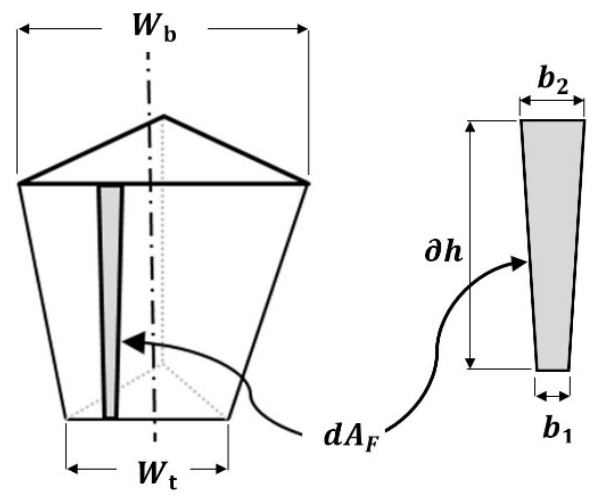

Figure 4. Schematic drawing of isosceles trapezoidal element to probe surface.

The element of area for one flat $\left(d A_{F}\right)$ can be expressed as (Figure 4):

$$
d A_{F}=\frac{1}{2} \cdot\left(E \cdot b_{2}+E \cdot b_{1}\right) \cdot \partial h
$$

Where $E$ is the number of trapezoidal elements on one flat.

While E. $b_{1}$ and $E . b_{2}$ are $\mathrm{wb}_{\mathrm{b}}$ and $\mathrm{w}_{\mathrm{t}}$ respectively so equation (9) can be rewritten as:

$$
d A_{F}=\frac{1}{2} \cdot\left(\partial w_{b}+\partial w_{t}\right) \cdot \partial h(10)
$$

While $\mathrm{w}_{\mathrm{t}}$ can be introduced as:

$$
\partial w_{t}=T_{r} . \partial w_{b}
$$

Where $T_{r}$ is taper ratio, for present work is 0.6 , so equation (10) can be simplified to:

$$
d A_{F}=\frac{\partial w_{b}}{2} \cdot\left(1+T_{r}\right) . \partial h
$$

By substitution equation (3) in equation (11) $d A_{F}$ can be expressed as:

$$
d A_{F}=\left(1+T_{r}\right) \cdot \sin \theta \cdot \partial r \cdot \partial h
$$

$d A$ calculates by substitution equation (12) in equations (8):

$$
\partial A=N \cdot\left(1+T_{r}\right) \cdot \sin \theta \cdot \partial r . \partial h(13)
$$

From equation (13) the probe factor $F_{P}$ is:

$$
F_{P}=N \cdot\left(1+T_{r}\right) \cdot \sin \theta(14)
$$

Finally, the equation (13) can be rewritten as:

$$
\partial A=F_{P} . \partial r . \partial h
$$

The $F_{P}$ value is listed at Table 2.

$x$ is shear force arm, i.e. it is the normal distance between the element area centre and probe central axis, its value for probe base, probe tip and probe surface can be calculated by:

$$
x=F_{R} \cdot r
$$

Where $F_{R}$ is a radius factor,

$F_{R}$ value for probe base and probe tip is (Figure 5):

$$
F_{R}=\frac{R_{\text {in_b }}}{R_{P}}=\frac{R_{P} \cdot \cos \theta}{R_{P}}=\cos \theta
$$

While $F_{R}$ for probe surface is:

$$
F_{R}=\frac{\left(R_{i n_{-}}+R_{i n_{-}} t\right)}{2 \cdot R_{P}}=\frac{\left(R_{P} \cdot \cos \theta+T_{r} \cdot R_{P} \cdot \cos \theta\right)}{2 \cdot R_{P}}
$$




$$
F_{R}=\frac{\cos \theta \cdot\left(1+T_{r}\right)}{2}
$$

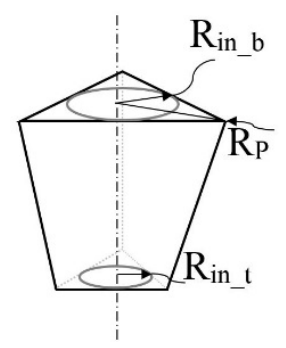

Figure 5. The radius of inscribed circle at probe base and probe tip cross section.

$F_{R}$ value for probe base and probe tip is listed in Table 1, while for probe surface is listed at Table 2.

\section{Heat generation in shoulder surface}

The heat generated from the shoulder surface $\left(Q_{1}\right)$ is calculated by subtracting the heat generated by the probe base area $\left(Q_{\mathrm{b}}\right)$ from the heat generated at the shoulder $\left(Q_{S}\right)$. The $\mathrm{Q}_{\mathrm{s}}$ can be calculated by substitution equation (7) and equation (16) in equation (1):

$$
Q_{S}=\int_{r=0}^{r=R_{S}} \omega \cdot \tau_{c o n} \cdot F_{R} \cdot r \cdot\left(F_{A} \cdot r \cdot \partial r\right)
$$

By substitution the values of $F_{R}$ and $F_{A}$ from Table 1. The $Q_{s}$ is:

$$
Q_{s}=\frac{2}{3} \pi \cdot \omega \cdot \tau_{c o n} \cdot R_{s}^{3}
$$

The heat generated by the probe base area $\left(Q_{\mathrm{b}}\right)$ can be expressed by substitution equation (7) and equation (16) at equation (1):

$$
Q_{\mathrm{b}}=\int_{r=0}^{r=R_{p}} \omega \cdot \tau_{c o n} \cdot F_{R} \cdot r \cdot\left(F_{A} \cdot r \cdot \partial r\right)
$$

By substitution the values of $F_{R}$ and $F_{A}$ from Table 1. The $\mathrm{Q}_{\mathrm{b}}$ is:

$$
Q_{\mathrm{b}}=\frac{2}{3} \cdot \pi \cdot \omega \cdot \tau_{c o n} \cdot\left(\frac{F_{R} \cdot F_{A}}{2 \pi}\right) \cdot R_{p}^{3}
$$

Table 1. The values of radius factor $\left(F_{R}\right)$ and area factor $\left(F_{A}\right)$.

\begin{tabular}{|c|c|c|}
\hline Cross section area & $\boldsymbol{F}_{\boldsymbol{R}}$ & $\boldsymbol{F}_{\boldsymbol{A}}$ \\
\hline Shoulder & $1^{*}$ & $2 \pi^{*}$ \\
\hline Triangular base and tip area & 0.5 & $0.827 \pi^{\dagger}$ \\
\hline Square base and tip area & 0.7 & $1.273 \pi^{\dagger}$ \\
\hline Pentagonal base and tip area & 0.8 & $1.512 \pi^{\dagger}$ \\
\hline Hexagonal base and tip area & 0.87 & $1.655 \pi^{\dagger}$ \\
\hline
\end{tabular}

${ }^{*}$ The value of $F_{R}$ and $F_{A}$ for shoulder is 1 and $2 \pi$ because $\mathrm{dA}$ element is circular.

${ }^{\dagger}$ The $F_{A}$ for non-circle cross section is a function of $\pi$.

Equation (18) can be rewritten to become:

$$
Q_{\mathrm{b}}=\frac{2}{3} \cdot \pi \cdot \omega \cdot \tau_{c o n} \cdot F_{1} \cdot R_{p}^{3}
$$

So, $Q_{1}$ is calculated from $Q_{s^{-}} Q_{b}$, i.e. Equations 17 and 19.

$Q_{1}=\frac{2}{3} \cdot \pi \cdot \omega \cdot \tau_{c o n} \cdot R_{s}^{3}-\frac{2}{3} \cdot \pi \cdot \omega \cdot \tau_{c o n} \cdot F_{1} \cdot R_{p}^{3}$

\section{Heat generation in probe surfaces}

Heat generated from probe surface $\left(Q_{2}\right)$ is expressed by substitution equation (15) and equation (16) at equation (1):

$$
Q_{2}=\int_{r=0}^{r=R_{p}} \int_{h=0}^{h=H_{p}} \omega \cdot \tau_{c o n} \cdot F_{R} \cdot r \cdot F_{P} \cdot \partial r . \partial h
$$


By substitution the values of $F_{R}$ and $F_{P}$ from

Table 2. The $Q_{2}$ is:

$$
Q_{2}=\frac{2}{3} \cdot \pi \cdot \omega \cdot \tau_{c o n} \cdot\left(\frac{3 \cdot F_{R} \cdot F_{P}}{4 \cdot \pi}\right) \cdot R_{p}^{2} \cdot H_{p}
$$

Equation (21) can be rewritten to become:

$$
Q_{2}=\frac{2}{3} \cdot \pi \cdot \omega \cdot \tau_{c o n} \cdot F_{2} \cdot R_{p}^{2} \cdot H_{p}
$$

Table 2. The values of radius factor $\left(\mathrm{F}_{\mathrm{R}}\right)$ and probe factor $\left(\mathrm{F}_{\mathrm{P}}\right)$.

\begin{tabular}{|c|c|c|}
\hline Tool profile & $\mathbf{F}_{\mathbf{R}}$ & $\mathbf{F P}^{\dagger}$ \\
\hline Triangular & 0.4 & $1.32 \pi$ \\
\hline Square & 0.56 & $1.43 \pi$ \\
\hline Pentagonal & 0.64 & $1.50 \pi$ \\
\hline Hexagonal & 0.69 & $1.53 \pi$ \\
\hline
\end{tabular}

${ }^{\dagger}$ The Fp for non-circle cross section is a function of $\pi$.

Heat generation in Probe tip crosssection

Probe tip area heat generated $\left(Q_{3}\right)$ can be expressed by substitution equation (7) and equation (16) at equation (1):

$$
Q_{3}=\int_{r=0}^{r=R_{t i p}} \omega \cdot \tau_{c o n} \cdot F_{R} \cdot r \cdot\left(F_{A} \cdot r \cdot \partial r\right)
$$

By substitution the values of $F_{R}$ and $F_{A}$ from Table 1. The $\mathrm{Q}_{3}$ is:

$$
Q_{3}=\frac{2}{3} \cdot \pi \cdot \omega \cdot \tau_{\text {con }} \cdot\left(\frac{F_{R} \cdot F_{A}}{2 \pi}\right) \cdot R_{\text {tip }}^{3}
$$

Equation (23) can be rewritten to become:

$$
Q_{3}=\frac{2}{3} \cdot \pi \cdot \omega \cdot \tau_{c o n} \cdot F_{3} \cdot R_{t i p}^{3}
$$

From equations 20, 22 and 24, QTotal is:
$Q_{\text {Total }}=\frac{2}{3} \cdot \pi \cdot \omega \cdot \tau_{\text {con }} \cdot\left[R_{s}^{3}-F_{1} \cdot R_{p}^{3}+F_{2} \cdot R_{p}^{2} \cdot H_{p}+\right.$ $\left.F_{3} \cdot R_{t i p}^{3}\right]$

Where F1, F2 and F3 are the values of heat generation equation factors. The values of these factors are listed in Table 3.

Table 3. Values of heat generation equation factors for different taper tool profiles.

\begin{tabular}{|c|c|c|c|}
\hline Tool profile & $\mathbf{F}_{\mathbf{1}}$ & $\mathbf{F}_{\mathbf{2}}$ & $\mathbf{F}_{\mathbf{3}}$ \\
\hline Triangular & 0.207 & 0.397 & 0.207 \\
\hline Square & 0.450 & 0.611 & 0.450 \\
\hline Pentagonal & 0.611 & 0.727 & 0.611 \\
\hline Hexagonal & 0.716 & 0.794 & 0.716 \\
\hline
\end{tabular}

\section{Validation}

The thermal-pseudo-mechanical model (TPM) for the different taper probe profiles (TR, SQ, PEN and HEX) was developed using the heat transfer module in COMSOL 5.1. The model geometry was symmetric around the weld. The aluminum alloy AA 2014-T6 plate dimensions were $320 \times 80 \times$ $5 \mathrm{~mm}$ as shown in Figure 6.

Tool rotational speed $(\mathrm{N})$, weld speed $\left(v_{w}\right)$ and axial force (Fn) were $1000 \mathrm{rev} / \mathrm{min}$, $600 \mathrm{~mm} / \mathrm{min}$ and $9 \mathrm{kN}$ respectively for all tool profiles to study the effect of change tool profile on the total heat generation. The temperature distribution was obtained from the steady-state conductive-convective energy equation (Equation 26) [15].

$$
\rho \cdot C_{P} \cdot u \cdot \nabla T=\nabla \cdot(k \cdot \nabla T)+Q
$$


Where $\rho$ is density, $C_{P}$ the specific heat, $u$ the velocity vector, $k$ thermal conductivity, $T$ the temperature, and $Q$ is the internal heat generation rate.

Two models (Model 1 and Model 2) were generated to predict the thermal profile for each tool with specific assumptions. These assumptions are listed in Table 4.

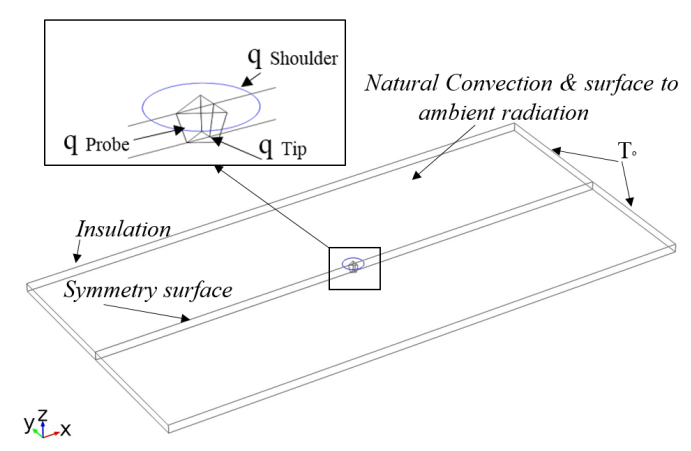

Figure 6. Model geometry for FSW.

Table 4. Assumptions for Models 1 and 2.

\begin{tabular}{|c|c|c|}
\hline Assumptions & Model 1 & Model 2 \\
\hline Friction coefficient $(\mu)$ & $\mu=0.3$ & $\mu=0.3$ \\
\hline $\boldsymbol{\tau}_{\text {sliding }}$ & $\tau_{s l}^{(1)}=\frac{\mu F_{n}}{A_{s}}$ & $\tau_{s l}^{(1)}=\frac{\mu F_{n}}{A_{s}}$ \\
\hline $\boldsymbol{\tau}_{\text {sticking }}$ & $\tau_{s t}=\frac{\sigma_{y_{(T)}}^{(2)}}{\sqrt{3}}$ & $\tau_{s t}=\frac{\sigma_{y_{(T)}}^{(2)}}{\sqrt{3}}$ \\
\hline Density $\left(\mathrm{kg} / \mathrm{m}^{\wedge} 3\right)$ & 2800 & $\rho_{(T)}{ }^{(3)}$ \\
\hline $\mathrm{THC}\left(\mathrm{W} /\left(\mathrm{m}^{*} \mathrm{~K}\right)\right)$ & 155 & $K_{(T)}{ }^{(4)}$ \\
\hline $\mathrm{HC}\left(\mathrm{J} /\left(\mathrm{kg}^{*} \mathrm{~K}\right)\right)$ & 880 & $C P_{(T)}{ }^{(5)}$ \\
\hline
\end{tabular}

${ }^{(1)}$ Shear contact stress under sliding condition $\left(\boldsymbol{\tau}_{\boldsymbol{s l}}\right)$ at shoulder interface in model land 2 is constant during FSW cycle.

(2) Shear contact stress under sticking condition $\left(\boldsymbol{\tau}_{\boldsymbol{s t}}\right)$ at probe surface and tip interface in model 1 and 2 is a function of temperature according to yield stress as a function of temperature $(\sigma y(\mathrm{~T}))$ as shown in Figure 7.

${ }^{(3)}$ Density in model 2 is a function of temperature $\left(\rho_{(T)}\right)$ calculated using equation (27).

${ }^{(4)}$ Thermal conductivity (THC) in modelling (2) is a function of temperature $\left(K_{(T)}\right)$ calculated using equation (28).
${ }^{(5)}$ Heat Capacity (HC) in modelling (2) is a function of temperature $\left(C P_{(T)}\right)$ calculated using equation (29).

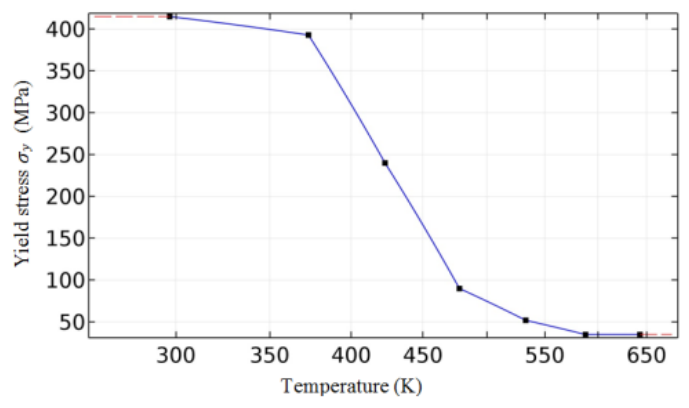

Figure 7. Temperature-dependent $0.2 \%$

offset yield strength for AA 2014-T6[22].

$$
\begin{aligned}
& \rho_{(T)}=-7 E^{-5} \cdot T^{2}-0.1415 . T+2855.2 \\
& K_{(T)}=-0.0001 \cdot T^{2}-0.1806 . T+116.55 \\
& C P_{(T)}=-7 E^{-5} \cdot T^{2}-0.4978 . T+734.93
\end{aligned}
$$

Where $\mathrm{T}$ is temperature.

The data of physical properties (density, thermal conductivity, heat Capacity) as a function of temperature in equations 27,28 and 29 are calculated by JMatPro software.

\section{Boundary Conditions and Initial \\ Condition}

The heat flux boundary condition for the workpiece at the tool shoulder / workpiece interface is $Q_{1}$. Similarly, the heat flux boundary conditions at the probe lateral surface / workpiece interface and the probe tip / workpiece interface are $Q_{2}$ and $Q_{3}$, respectively. The inbuilt material properties in COMSOL5.1 (density, thermal conductivity and heat capacity) for the AA 2014-T6 aluminium alloy were considered, and for AISI H13 tool steel, are as follows: 
thermal conductivity $-28.7 \mathrm{~W} /(\mathrm{m} \mathrm{K})$, density $-7760 \mathrm{~kg} / \mathrm{m}^{3}$, and heat capacity at constant pressure $-460 \mathrm{~J} /(\mathrm{g} \mathrm{K})$ [23]. The friction coefficient $(\mu)$ was assumed constant at 0.3 [7].

\section{Boundary Conditions}

The heat loss form upper plate's surface due convection and radiation, it can be expressed as:

$$
\left.k \frac{\delta T}{\delta n}\right|_{\Gamma}=\varepsilon \sigma\left(T_{o}^{4}-T^{4}\right)+h_{u p}\left(T-T_{o}\right)
$$

Convection boundary condition for lowerbase metal surface contacts with backup plate can be expressed as:

$$
\left.k \frac{\delta T}{\delta n}\right|_{\Gamma}=h_{\text {down }}\left(T-T_{o}\right)
$$

Where $k$ is heat conductivity, $\varepsilon$ is the emissivity, $T$ is temperature, $n$ is a normal direction vector of boundary $\Gamma, h_{u p}$ and $h_{\text {down }}$ are convection coefficients for lower and upper-base metal surfaces and $T_{o}$ is Initial temperature.

In present project, $h_{u p}$ and $h_{\text {down }}$ have different values because there is a contact between lower surface and backup plate. In the present study, it is considered as $\mathbf{1 2 . 2 5}$ and $6.25 \mathrm{~W} / \mathrm{m}^{2} \mathrm{~K}$, respectively. The emissivity $(\varepsilon)$ was assumed 0.3 [7].

\section{Initial condition}

The initial condition for the calculation is:

$$
T(x, y, z, 0)=T_{o}
$$

Where $\mathrm{T}$ is temperature, $T_{o}$ is Initial temperature.

\section{Discussion}

Figure 8 A-D shows that peak temperature increases with number of flats TR (724K), and SQ (743K), PEN (758K), and HEX tool profile (764K). Kadian and Biswas [24] also showed that peak temperature increases with the increase polygon probe sides. The present calculated results were about $81.5-83.6 \%$ of melting point. Biswas and Mandal [11] investigated the effect of tool profile on thermal profile. Their finding pointed that the ratio of peak temperature to melting point is more than $80 \%$. Tikader, Biswas [25] reported the ratio of peak temperature to melting point is increased by $10 \%$ with increase probe diameter $1 \mathrm{~mm}$. While Figure 9 compares peak temperature for different taper tool profiles under model $1 \& 2$ assumptions. It can be seen that the peak temperature increases by increasing number of flats on probe lateral surface in model 1 (TR (755K), and SQ (775K) PEN (791K), and HEX (798K)). In contrast, model 2 results showed the lowest peak temperatures compared with model 1. 
Model 2 results has a good agreement with previous practical study [18] because it was considered the effect of change physical material properties (density, thermal conductivity and heat capacity ) with temperature on the thermal profile during welding cycle. HEX probe profile has the highest peak temperature because increase the number of flats in probe surface lead to increased deformation rate as a result of increasing stirring interaction and reducing rotating layer thickness[18] by a decrease effective stir dimension (the difference between inside and outside polygon radius for probe cross section).

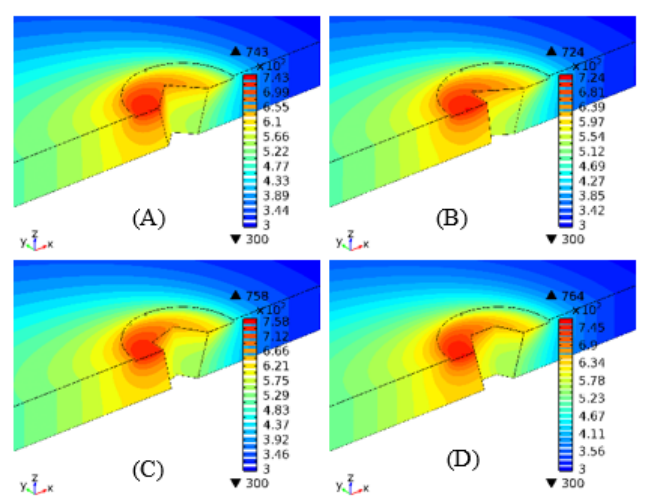

Figure 8. Isotherms temperature distribution for different probe profiles: ATR, B- SQ, C-PEN and D-HEX (model 2).

Modelling results for present work is compared with experimental data measured by Ramanjaneyulu, Reddy [18] by calculating temperature at specific point $3 \mathrm{~mm}$ from welding line $\left(\mathrm{T} \_3 \mathrm{~mm}\right)$ at mid thickness of plate because Rammanjaneulu measured temperature at a point close to probe (approximately $3 \mathrm{~mm}$ ).

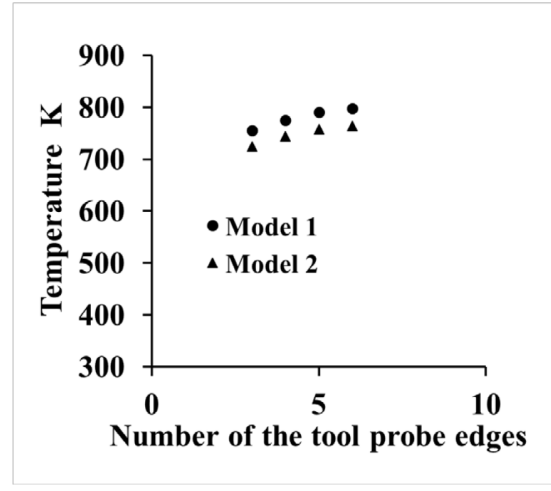

Figure 9. Comparison between modelling results for present work.

Good agreement is observed as shown in Figure 10. The variation between numerical model 1 results and practical results for Ramanjaneyulu, Reddy [18] is attributed due to the following two reasons: First reason is the material properties such as thermal conductivity, heat capacity, and density for the workpiece are assumed constant and the second reason is the friction coefficient was assumed constant. The modelling results for present work are also compared with numerical modelling results by Gadakh, Kumar [12] who built their modelling according to practical results for Ramanjaneyulu, Reddy [18] as shown in Figure 10. 


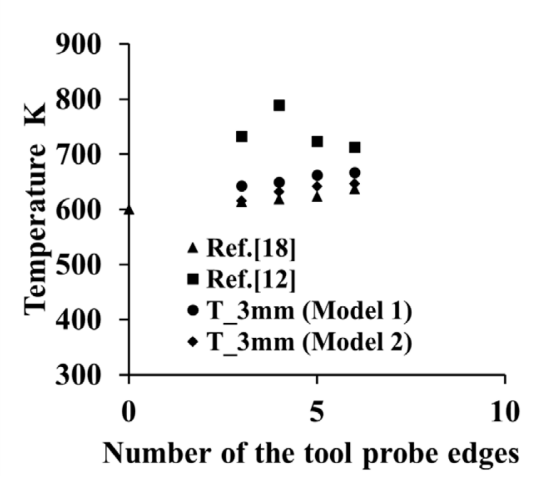

Figure 10. Comparison among modelling results for present work, experimental results[18], and modelling results[12] for the temperature with the number of polygon sides.

Present work model 2 results are closer to experimental data measured by Ramanjaneyulu, Reddy [18] than Gadakh, Kumar [12] because the probe profile geometry factor (F2) were calculated in present work are less than values were calculated by Gadakh, Kumar [12] as shown in Table 5. In addition, Gadakh, Kumar [12] did not consider the change in lateral probe area which is changed with taper ratio.

Table 5. Multiplying Factor $\left(\mathrm{F}_{2}\right)$ different probe profiles.

\begin{tabular}{|c|c|c|}
\hline Probe profile & $\begin{array}{c}\mathrm{F}_{2} \text { (Tapered) } \\
\text { (our study) }\end{array}$ & $\begin{array}{c}\mathrm{F}_{2} \text { (straight) } \\
\text { (ref.[12]) }\end{array}$ \\
\hline Triangular & $\mathbf{0 . 3 9 7}$ & $\mathbf{0 . 7 2}$ \\
\hline Square & $\mathbf{0 . 6 1 1}$ & $\mathbf{0 . 9 5}$ \\
\hline Pentagonal & $\mathbf{0 . 7 2 7}$ & $\mathbf{1 . 1 9}$ \\
\hline Hexagonal & $\mathbf{0 . 7 9 4}$ & $\mathbf{1 . 4 3}$ \\
\hline
\end{tabular}

\section{Conclusions}

\section{Equations}

Equations for heat generation in FSW have been derived for different taper tool profile such as TR, SQ, PEN, and HEX, The major finding from the present work can be summarized as follow:

- The amount of heat generation from shoulder surface decrease with increasing of flats on the probe surface as a result of increase probe base area.

- The contribution of probe surface at total heat generation increases with increasing of flats on the probe surface as a result of increase deformation rate and contact area.

- The contribution of probe tip at total heat generation increases with increasing of flats on the probe surface as a result of increase contact area.

\section{Validation}

An analytical model for heat generation in FSW of aluminium alloy type AA 2014-T6 using different taper tool profiles such as TR, SQ, PEN, and HEX are developed. The major finding from the present work can be summarized as follow: 
- The amount of heat generated as well as peak temperature are relatively high in non-circular taper probe profiles, they increase by increasing the number of edges for TR, SQ and PEN to reach maximum values in the HEX tool profile.

- The effective stir dimension is decreased by increasing number of flats on surface probe profile.

- An increase number of effective stir dimension with increasing the number of flats on probe surface lead to increasing the total heat generation.

By using the proposed analytical approach, we can predict the mechanical properties of a specific aluminium alloy by correlating the peak temperature for respective tool geometry under given FSW process conditions with the precipitate phase distribution and grain size.

\section{Acknowledgements}

The first and second author gratefully acknowledges the support provided by the Iraqi Ministry of Higher Education and Scientific Research (IMHESR) for funding this work through scholarship no. 4956 for the first author and no. 2872 for the second author.

\section{References}

1. Tang, W., et al., Heat input and temperature distribution in friction stir welding. Journal of Materials Processing and Manufacturing Science, 1998. 7: p. 163-172.

2. Schwartz, M.M., Brazing. 2003: ASM international.

3. Thomas, W., et al., Friction stir welding. International patent application no. PCT/GB92102203 and Great Britain patent application, 1991(9125978.8).

4. Frigaard, Ø., et al. Modelling of the thermal and microstructure fields during friction stir welding of aluminium alloys. in International Friction Stir Welding Symposium, Thousand Oaks, CA. 1999.

5. Sato, Y., et al., Experimental verification of heat input during friction stir welding of Al alloy 5083. Science and Technology of Welding and Joining, 2016. 21(4): p. 325-330.

6. Đurđanović, M., et al., Heat generation during friction stir welding process. Tribology in industry, 2009. 31(1-2): p. 8-14.

7. Schmidt, H., J. Hattel, and J. Wert, An analytical model for the heat generation in friction stir welding. Modelling and Simulation in Materials Science and Engineering, 2003. 12(1): p. 143.

8. Bastier, A., et al., Steady state thermomechanical modelling of friction stir welding. Science and Technology of Welding and Joining, 2006. 11(3): p. 278-288.

9. Zhang, X., B. Xiao, and Z. Ma, $A$ transient thermal model for friction stir weld. Part I: the model. Metallurgical and Materials Transactions A, 2011. 42(10): p. 3218-3228.

10. Zhang, X., B. Xiao, and Z. Ma, $A$ transient thermal model for friction stir weld. Part II: Effects of weld conditions. Metallurgical and Materials 
Transactions A, 2011.42(10): p. 32293239.

11. Biswas, P. and N. Mandal, Effect of tool geometries on thermal history of FSW of AA1100. Welding Journal, 2011. 90(Suppl): p. 129-135.

12. Gadakh, V., A. Kumar, and G.V.Patil, Analytical Modeling of the Friction Stir Welding Process Using Different Pin Profiles. Welding Journal, 2015. 94(4): p. 115S-124S.

13. Trueba, L., et al., Effect of tool shoulder features on defects and tensile properties of friction stir welded aluminum 6061-T6. Journal of Materials Processing Technology, 2015. 219: p. 271-277.

14. Elangovan, K. and V.

Balasubramanian, Influences of tool pin profile and tool shoulder diameter on the formation of friction stir processing zone in AA6061 aluminium alloy. Materials \& design, 2008. 29(2): p. 362-373.

15. Colegrove, P.A., 3 Dimensional flow and thermal modelling of the friction stir welding process. 2002: University of Adelaide, Department of Mechanical Engineering.

16. Neto, D.M. and P. Neto, Numerical modeling of friction stir welding process: a literature review. The International Journal of Advanced Manufacturing Technology, 2013. 65(1-4): p. 115-126.

17. Schmidt, H.B. and J.H. Hattel, Thermal modelling of friction stir welding. Scripta Materialia, 2008. 58(5): p. 332337.

18. Ramanjaneyulu, K., et al., Structureproperty correlation of AA2014 friction stir welds: role of tool pin profile. Journal of materials engineering and performance, 2013. 22(8): p. 22242240.

19. Sun, Z., C. Wu, and S. Kumar, Determination of heat generation by correlating the interfacial friction stress with temperature in friction stir welding. Journal of Manufacturing Processes, 2018. 31: p. 801-811.

20. Gadakh, V.S. and K. Adepu, Heat generation model for taper cylindrical pin profile in FSW. Journal of Materials Research and Technology, 2013. 2(4): p. 370-375.

21. He, X., F. Gu, and A. Ball, A review of numerical analysis of friction stir welding. Progress in Materials Science, 2014. 65: p. 1-66.

22. Handbook, A., Nonferrous Alloys and Special-purpose Materials, vol. 2. ASM International, OH, 1990.

23. Davis, J.R., K. Mills, and S. Lampman, Metals handbook. Vol. 1. Properties and selection: Irons, steels, and highperformance alloys. ASM International, Materials Park, Ohio 44073, USA, 1990. 1063, 1990.

24. Kadian, A.K. and P. Biswas, Effect of tool pin profile on the material flow characteristics of AA6061. Journal of Manufacturing Processes, 2017. 26: $\mathrm{p}$. 382-392.

25. Tikader, S., P. Biswas, and A.B. Puri, $A$ study on tooling and its effect on heat generation and mechanical properties of welded joints in friction stir welding. Journal of The Institution of Engineers (India): Series C, 2018. 99(2): p. 139150. 


\section{A list of figure captions}

Figure 1. Geometry of various taper tool profiles. .4

Figure 2. Schematic drawing of surface orientations and infinitesimal segment. (a) Shoulder surface area, (b) Probe surface area and (c) Probe base and tip crosssection area.

Figure 3. Schematic drawing for probe base. (a) The triangular probe base cross section. (b) Schematic drawing for Position and dimensions of segment .5

Figure 4. Schematic drawing of isosceles trapezoidal element to probe surface. .......6 Figure 5. The radius of inscribed circle at probe base and probe tip cross section......7 Figure 6. Model geometry for FSW.........9 Figure 7. Temperature-dependent $0.2 \%$ offset yield strength for AA 2014-T6[22].9 Figure 8. Isotherms temperature distribution for different probe profiles: ATR, B- SQ, C-PEN and D-HEX (model 2).
Figure 9. Comparison between modelling results for present work 11 Figure 10. Comparison among modelling results for present work, experimental results[18], and modelling results[12] for the temperature with the number of polygon sides. 